\title{
(2) OPEN ACCESS \\ Short-term rate of milk synthesis and expression interval of preterm mothers
}

\author{
Ching Tat Lai $\odot$, ${ }^{1}$ Alethea Rea, ${ }^{1}$ Leon R Mitoulas, ${ }^{2}$ Jacqueline C Kent, ${ }_{1}^{1}$ Karen Simmer, ${ }^{3}$ \\ Peter Edwin Hartmann, ${ }^{1}$ Donna Geddes ${ }^{1}$
}

\begin{abstract}
- Additional material is published online only. To view please visit the journal online (http://dx.doi.org/10.1136/ archdischild-2018-316551).

'Department of Molecular Sciences, The University of Western Australia, Crawley, Western Australia, Australia ${ }^{2}$ Medela AG, Baar, Switzerland ${ }^{3}$ Department of Paediatrics, The University of Western Australia, Crawley, Western Australia, Australia
\end{abstract}

Correspondence to Dr. Ching Tat Lai, Molecular Science, The University of Western Australia, Crawley, WA 6009, Australia; ching-tat.lai@uwa.edu.au

Received 16 November 2018 Revised 1 June 2019 Accepted 27 June 2019 Published Online First 10 July 2019

\section{ABSTRACT}

Aim To determine the impact of the pumping regimes of women with preterm infants on the daily milk production, and on the short-term rate of milk synthesis during early lactation to support evidence-based recommendations for optimising milk production. Methods Mothers of preterm infants $(n=25)$ recorded start time, finish time and expression volumes from every breast expression on days 10, 15-20 postpartum. Results Expressing more often than five times per day did not result in a significant increase in daily milk production. Milk volume per expression per breast increased for intervals between expressions of between 2and6 hours then reached a plateau when the interval between expression was 7 hours or longer. The shortterm rate of milk synthesis decreased as the interval between expressions increased until about 7.5 hours at which point it begun to increase ( $p$ value associated with interval between expressions $\wedge 2<0.001$ ).

Conclusion The strong inverse association between the short-term rate of milk synthesis and the interval between expressions for intervals up to 7 hours suggest that the maximum interval between expressions should be 7 hours. Data suggest that, on average, the mothers should express at least five times a day to maximise daily milk production. Considering inter-individual variation, determination of an individual mother's maximum interval between expressions that does not compromise the short-term rate of milk synthesis will help to optimise daily milk production while minimising the demands on the mother's time.

\section{INTRODUCTION}

Women who deliver prematurely are encouraged to provide their own milk for their infants because a human milk diet in the neonatal intensive care unit is associated with improvements in host defences, digestion and absorption of nutrients, gastrointestinal function, neurodevelopment and a lower rate of necrotising enterocolitis. ${ }^{12}$ Necrotising enterocolitis is a devastating gastrointestinal disease in preterm infants, especially in very low birthweight preterm infants. ${ }^{3}$ Introduction of human milk or donor human milk as early as within 48 hours of birth could result in a decline in the rate of necrotising enterocolitis from $4.1 \%$ to $0.4 \%{ }^{4}$

Mothers of preterm infants typically use breast pumps to express milk for their infants because of the inability of preterm infants of $<34$ weeks of gestation to effectively coordinate sucking, swallowing and breathing. ${ }^{5}$ Early and frequent expression also increases the probability of establishing

\section{What is already known on this topic?}

- For mothers of preterm infants, frequency of breast expressions per day is positively related to both daily and weekly milk production.

- Common advice includes expression at least six times a day.

- Long intervals between expressions have been shown to slow the rate of short-term rate of milk synthesis.

\section{What this study adds?}

- We have shown a higher short-term rate of milk synthesis when the interval between expressions is shorter, but there are differences between individuals.

- Determining mother's maximum interval between expressions without compromising short-term rate of milk synthesis could optimise milk production while reducing the demands on the mother's time.

a full milk supply adequate to meet the infants' needs. There is strong evidence that the frequency of breast expressions per day is positively related to both daily and weekly milk production. ${ }^{6-9}$ Therefore, the common advice is to encourage mothers of preterm infants to expression 8-10 times day and double pumping when possible. However, mothers might not be able to follow this advice due to the level of support that they have. ${ }^{10}$

In addition, high frequency of expression reduces the interval between expressions and promotes increased milk production because long intervals between expressions have been shown to slow the rate of short-term rate of milk synthesis in mothers of term infants. ${ }^{11}$

The aim of this observational study was to determine the impact of the pumping regimes of women with preterm infants on the daily milk production, and on the short-term rate of milk synthesis during early lactation to support evidence-based recommendations for optimising milk production.

\section{METHODS AND MATERIALS}

Subjects

Participants were recruited in special care baby nursery of King Edward Memorial Hospital, Subiaco, Western Australia. 
Table 1 Maternal and infant characteristics

\begin{tabular}{lcccc}
\hline & Median & IQR & Minimum & Maximum \\
\hline Maternal age & 34 & 4.5 & 23 & 44 \\
Maternal height & 165 & 7.5 & 151 & 180 \\
Maternal weight & 70 & 10.5 & 58 & 90 \\
Maternal BMI & 25.71 & 4.87 & 18.83 & 35.16 \\
Infant gestational age & 29 & 4 & 24 & 32 \\
Infant birth weight & 1270 & 375 & 500 & 2155 \\
\hline
\end{tabular}

Inclusion criteria: Participants were 18 years or older, had delivered before 34 weeks of gestation, intended to breast feed, had initiated their lactation by day 8 postpartum and were expressing breast milk for their infant but had not begun breast feeding.

Exclusion criteria: Individuals were excluded from recruitment if they did not intend to express breast milk for their infants from days 10 to 20 postpartum or if the infant was not expected to survive.

Participants $(n=25)$ provided written informed consent to participate in the study, which was approved by the Human Research Ethics Committee of King Edward Memorial Hospital, Western Australia (818/EW). Ethics approval only allowed recruitment and participation of mothers after day 8 postpartum.

\section{Data recording and measures}

Participants followed the breast expression instructions provided by the lactation consultant in hospital. Participants recorded all expressions on days 10, 15-20 postpartum. All participants used the electric pump (Symphony, Medela AG, Switzerland) for all expression sessions. In all, 23 participants were expressing simultaneously and two participants were expressing sequentially. This record included the starting and finishing time of each expression from each breast and the volume of milk per expression (by weighing the bottle before and after each expression). Where breast feeds commenced within the study period, milk volumes were recorded by test-weighing the infant with a digital scale (BabyWeigh; Medela, McHenry, IL; resolution, $2 \mathrm{~g}$; accuracy, $0.034 \%$ ) before and after the each breast feed. ${ }^{12}$ Therefore, all volumes are expressed in grams because the density of milk is $1.03 \mathrm{~g} / \mathrm{mL}^{13}$

Daily milk production was calculated as the sum of amount of milk from both breasts from midnight to midnight. Milk transfer during breast feeding was added where appropriate. The interval between expressions was defined as the period between the end of one breast expression and the end of the subsequent breast expression. The short-term rate of milk synthesis was calculated as the volume of milk of each expression divided by the interval between expressions. A pumping regime was defined as the

Table 2 Breast expression characteristics

\begin{tabular}{lcccc}
\hline & Median & IQR & Minimum & Maximum \\
\hline Volume per expression (g) & 52 & 42.65 & 1.8 & 2.57 \\
Volume per expression (left breast) (g) & 53 & 37 & 5 & 257 \\
Volume per expression (right breast) (g) & 49.8 & 50.8 & 1.8 & 243 \\
$\begin{array}{l}\text { Duration per expression (minute) } \\
\text { Short-term rate of milk synthesis (g/ }\end{array}$ & 17.5 & 10 & 4 & 80 \\
hour) & 16.2 & 12.7 & 1.1 & 106.6 \\
Number of expressions per day & 6 & 1 & 3 & 9 \\
Daily milk volume (g) & 676.9 & 462.5 & 139.4 & 1801 \\
\hline
\end{tabular}

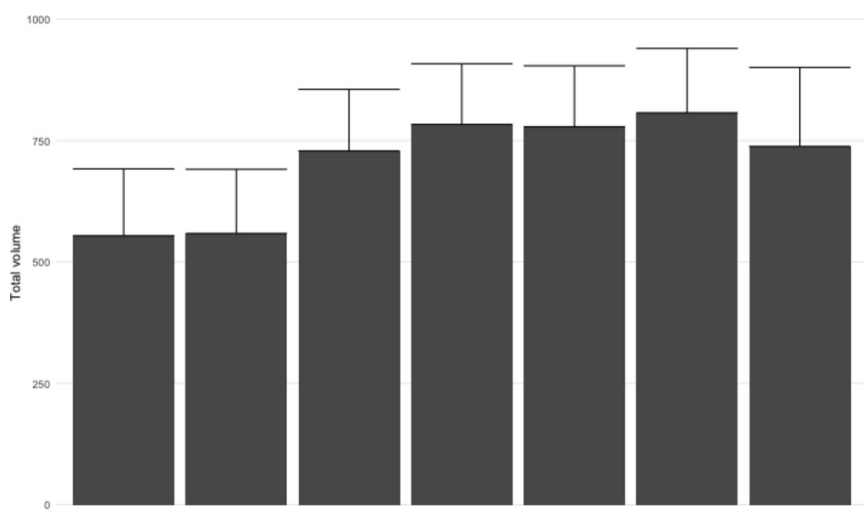

Figure 1 Expected (plus one standard error) daily milk production according to pumping regime ( $n=162$, one missing value) based on modelling.

frequency of expressions on a given day; therefore, mothers can have a different regime on different days.

\section{Statistics}

Demographic and expression summaries are presented as median $\pm \mathrm{IQR}$ (range).

We analysed volume per expression as explained by frequency of expression and intervals between expressions (as a polynomial of degree 2). We also analysed the rate as explained by intervals between expression. Additionally, we modelled daily volumes were explained by frequency. All models fitted were linear mixed effect models with a random effect for participant. Contrasts were examined for all pairwise comparisons with Tukey corrections. Significance was set at the 5\% level and data were analysed using the $\mathrm{R}$ environment for statistical computing. ${ }^{14}$

\section{RESULTS}

In all, 25 participants consented to being in the study. In total, 17 participants were begun data recording on day 10 postpartum while eight participants were begun data recording on day 15 postpartum (online supplementary table 1). Due to personal commitments, data were missing for one participant for days 17-18 postpartum, one participant for days 17-20 postpartum and one participant for day 20 postpartum. One participant attempted to breast feed for one session on day 17 postpartum.

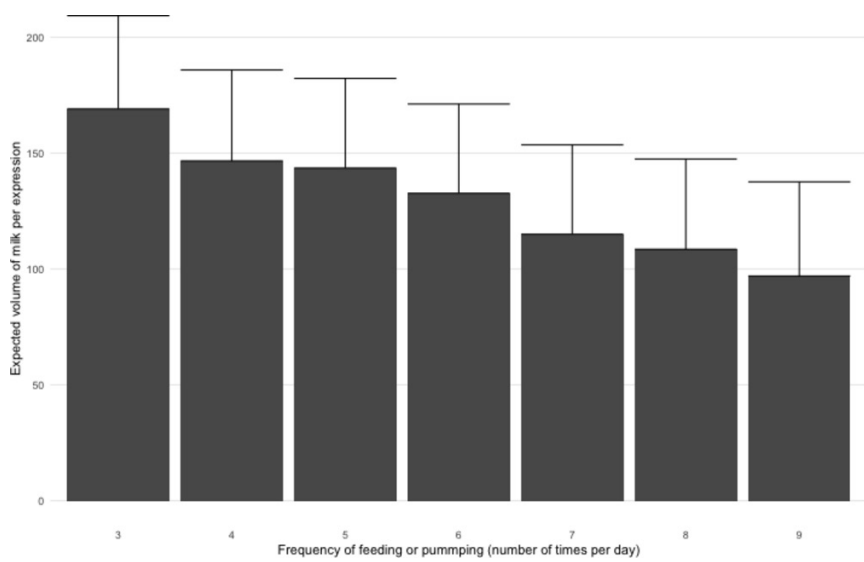

Figure 2 Expected (plus one standard error) volume of milk per expression for preterm mothers for different pumping regimes $(n=1886$ individual expressions). 
Table 3 Volume of milk per expression $(\mathrm{g})$ for different pumping regimes (shown in figure 2), mean difference estimates from a linear mixed model $(\mathrm{g})(95 \% \mathrm{Cl}$, p value)

\begin{tabular}{|c|c|c|c|c|c|c|}
\hline $\begin{array}{l}\text { Number of } \\
\text { expressions } \\
\text { per day }\end{array}$ & 4 & 5 & 6 & 7 & 8 & 9 \\
\hline 3 & $11.5(-3$ to $26.0,0.226)$ & $12.8(-1.2$ to $6.9,0.097)$ & 17.9 (3.4 to $32.4,0.005)$ & $26.9(11.9$ to $41.8,<0.001)$ & $30.1(13.6$ to $46.7,<0.001)$ & $35.8(14.4$ to $57.3,<0.001)$ \\
\hline 4 & & $1.4(-7.6$ to $10.4,0.999)$ & $6.5(-3.8$ to $16.7,0.509)$ & 15.4 (4.5 to $26.2,<0.001)$ & $18.6(5.7$ to $31.4,<0.001)$ & $24.4(5.5$ to $43.2,0.003)$ \\
\hline 5 & & & $5.1(-0.7$ to $10.7,0.124)$ & $14.0(7.2$ to $20.8,<0.001)$ & 17.2 (7.6 to $26.8,<0.001)$ & $23.0(6.1$ to $39.8,0.001)$ \\
\hline 6 & & & & $8.9(4.7$ to $13.1,<0.001)$ & 12.2 (4.0 to $20.3,0.003$ ) & $17.9(1.9$ to $33.8,0.017)$ \\
\hline 7 & & & & & $3.2(-4.4$ to $10.9,0.878)$ & $9.0(-6.5$ to $24.4,0.609)$ \\
\hline 8 & & & & & & $5.7(-10.9$ to $22.4,0.950)$ \\
\hline
\end{tabular}

The maternal, infant and breast expression characteristics are summarised in tables 1 and 2, respectively.

The daily milk production was associated with pumping regime (frequency of expressions). Comparing three expressions a day to four, five and six there was no significant increase between three and four expressions or three and five expressions, but an increase between three and six expressions (228 $\mathrm{g}$ (95\% CI: 43 to 414), $\mathrm{p}=0.006$ ). Comparing four expressions a day to five and six, there were increases for both (five: $170 \mathrm{~g}$ (95\% CI: 42 to 298$), p=0.002$, six: 223 g (95\% CI: 77 to 370$)$, $\mathrm{p}<0.001)$. However, the daily milk production was no difference found when comparing between frequency of expressions of five, six, seven, eight and nine times (95\% CI: -317 to 332 , $\mathrm{p}=1$ ). The daily milk production according to pumping regime is shown in figure 1 .

The volume of milk per expression according to pumping regime is shown in figure 2. Tukey post-hoc comparisons showed differences between pumping regimes in volume of milk per expression (table 3).

The volume of milk per expression was not linear with interval between expressions (figure 3) but increased for intervals of between 2 and 6 hours and reached a plateau for intervals greater than 7 hours.

The short-term rate of milk synthesis is modelled with a polynomial of degree 2 giving the following equation: short-term rate $=32.38-5.26 *$ interval between expressions $+0.32 \%$ interval between expressions $\wedge 2$ ( $\mathrm{p}$ value associated with interval between expressions $\wedge 2<0.001$ ) (figure 4 ).

\section{DISCUSSION}

The short-term rate of milk synthesis was affected by the interval between breast expressions, showing the rate of milk synthesis was decreasing with longer intervals between expressions. The larger volume of milk per expression after longer intervals (figure 3) or when there are fewer expressions per day (figure 2) may give mothers a false impression that they produce more milk if they express less frequently. However, the current results concur with previous findings that higher daily milk production is associated with more expressions per day. ${ }^{8}$

The relationship between the short-term rate of milk synthesis and the interval between breast expressions is consistent with the results of Daly et al (1996) for four-term mothers. They showed that the short-term rate of milk synthesis was lower than the average for each mother after $6,7,8$ and 12 hours for the four mothers studied. The decrease in the short-term rate of milk synthesis after longer intervals between expressions may be attributed to autocrine control. ${ }^{1516}$ The less thoroughly the breast is drained, the lower the subsequent rate of milk synthesis. ${ }^{15}$ When mothers express every hour, the volume of milk removed per expression is consistently more for the first two expressions compared with subsequent hourly expressions. ${ }^{17} 18$ These results imply that the breast was not thoroughly drained after the first expression, which occurred at various intervals from the previous expression or breast feed, and the breasts were at different degrees of fullness. It has been demonstrated that when more milk is present in the breast less of the available milk is removed during a single expression. ${ }^{19}$ In that case, the drainage

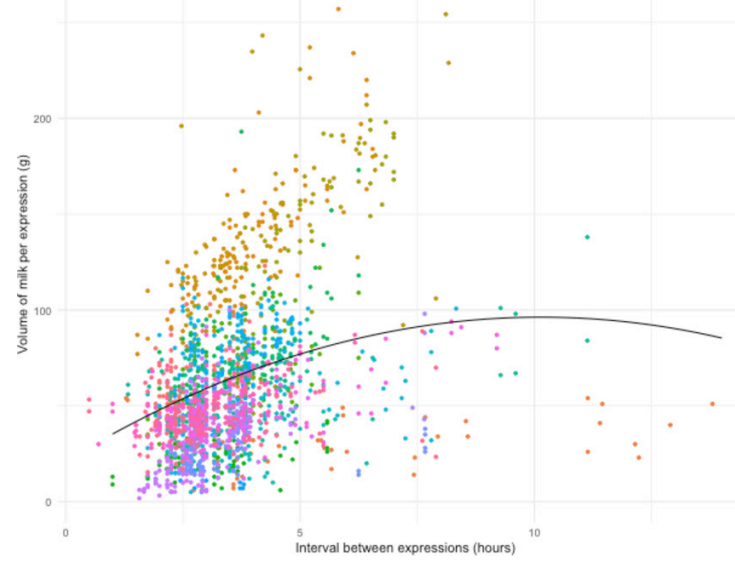

Figure 3 Relationship between the volume of milk per expression ( $\mathrm{g}$ ) and the interval between expressions (hours) for preterm mothers. Fitted model (solid line) and individual expressions from each mother, each participant represented by a colour, $\mathrm{n}=1886$.
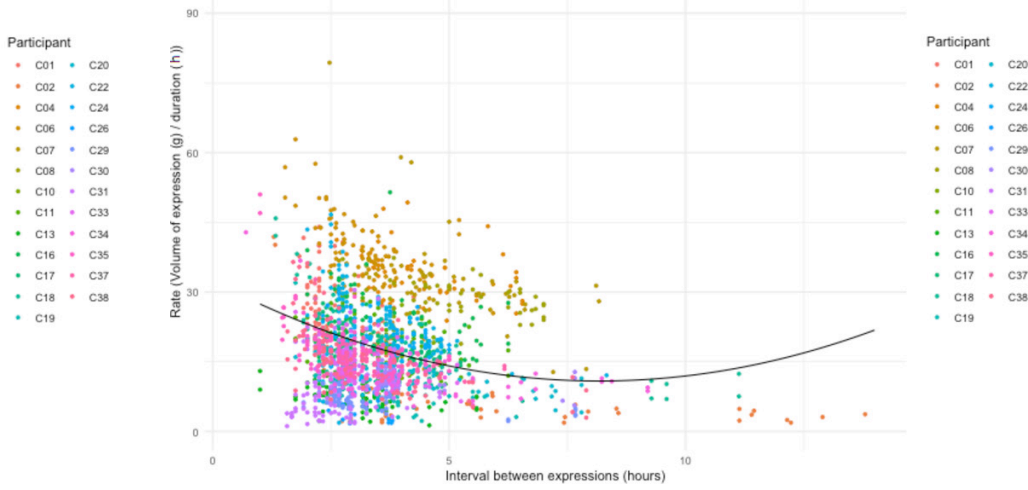

Figure 4 Relationship between the short-term rate of milk synthesis $(\mathrm{g} / \mathrm{h})$ and the interval between expressions (hours). Fitted model (solid line) and individual expressions from each mother, each participant represented by a colour, $\mathrm{n}=1886$. 
of the breast will be less complete and the subsequent rate of milk synthesis will be compromised. ${ }^{11}$ Therefore, to increase daily milk production, it is important to optimise the interval between expressions so that the residual milk in breast is minimised. This would, in turn, minimise the autocrine inhibition of milk synthesis and maintain an optimal rate of milk synthesis. Hence, consideration should be given not just to the number of expressions per day but to the longest interval between expressions to optimise milk production.

The standard advice for increasing milk production in pre-term mothers is to increase the frequency of expressions. While the current results support this concept in principle, analysis of the short-term rate of milk synthesis suggests that the focus should be on the interval between expressions rather than simply on the number of expressions per day. Data shown in figure 4 indicate that the average short-term rate of milk after an interval between expressions of 4 hour is $15 \mathrm{~g} / \mathrm{h}$ per breast. That is, expressing at regular intervals six times a day results in a daily milk production of $720 \mathrm{~g}$. Although there was no significant difference in volume of milk per expression between pumping regimes of four or six expressions per day (figure 2), fewer expressions would have a negative impact on daily milk production.

The lower short-term rate of milk synthesis for intervals of more than 5 hours (figure 4) reinforces the suggestion that the number of expressions should be distributed over the day ensuring that there are no extended intervals between expressions. The actual maximum interval between expressions may be different for each breast. However, from a practical point of view, it would be difficult to apply different pumping regimes to each of the mother's breasts, and advice should be based on the breast that is more sensitive to intervals between expressions.

It has been shown that milk production in mothers of preterm infants who were expressing breast milk for their infants at week 2 is related to milk production at week $6{ }^{20}$ Therefore, we suggest that application of the results of the current study to optimise milk expression in this early period will be advantageous for the subsequent lactation period.

\section{LIMITATIONS}

Although this observational study had a small sample size $(\mathrm{n}=25)$, we were able to collect over 1500 individual milk volume results on day $10,15-20$ postpartum. It illustrates the strong associations between short rate of milk synthesis, milk volume per expression and interval between expressions, that needs to be considered when optimising individual expression regime that mother is willing to carry on without compromising the provision of her own milk to her infant.

\section{CONCLUSION}

There is a strong inverse association between the short-term rate of milk synthesis and the interval between expressions for intervals up to 7 hours. Data suggest that, on average, the maximum interval between expressions should be 7 hours, and mothers should express at least five times a day. Considering inter-individual variation, we suggest that the determination of an individual mother's maximum interval between expressions that does not compromise the short-term rate of milk synthesis will help to optimise daily milk production while minimising the demands on the mother's time.

Acknowledgements We would like to thank all mothers who participated in this research. Funding for this study was provided by an unrestricted research grant and a scholarship from Medela AG, Baar, Switzerland.
Contributors CTL performed literature search, data collection, data analysis, data interpretation, writing and submitting of the manuscript. AR was involved in data analysis and critically reviewed the manuscript. JCK and LM were involved in interpretation of the data and critically reviewed the manuscript. PEH, KS and DTG were involved in the supervision of the study, acquisition of funding and critically reviewed the manuscript. All authors were approved the final version of the manuscript.

Funding Funding for this study was provided by an unrestricted research grant from Medela AG, Baar, Switzerland.

Competing interests None declared.

Patient consent for publication Not required.

Ethics approval The Ethics Committee of King Edward Memorial Hospital (818/ EW).

Provenance and peer review Not commissioned; externally peer reviewed.

Data sharing statement The deidentified data that used and presented in this study can be obtained from the corresponding author.

Open access This is an open access article distributed in accordance with the Creative Commons Attribution Non Commercial (CC BY-NC 4.0) license, which permits others to distribute, remix, adapt, build upon this work non-commercially, and license their derivative works on different terms, provided the original work is properly cited, appropriate credit is given, any changes made indicated, and the use is non-commercial. See: http://creativecommons.org/licenses/by-nc/4.0/.

\section{ORCID iD}

Ching Tat Lai http://orcid.org/0000-0002-9025-4922

\section{REFERENCES}

1 Boyd CA, Quigley MA, Brocklehurst P. Donor breast milk versus infant formula for preterm infants: systematic review and meta-analysis. Arch Dis Child Fetal Neonatal Ed 2007;92:F169-75

2 Schanler RJ, Hurst NM, Lau C. The Use of Human Milk and Breastfeeding in Premature Infants. Clin Perinatol 2018.

3 Denning NL, Prince JM. Neonatal intestinal dysbiosis in necrotizing enterocolitis. $\mathrm{Mol}$ Med 2018:24:4

4 Feinberg M, Miller L, Engers B, et al. Reduced Necrotizing Enterocolitis after an Initiative to Promote Breastfeeding and Early Human Milk Administration. Pediatr Qual Saf 2017;2:e014.

5 Lau C, Smith EO, Schanler RJ. Coordination of suck-swallow and swallow respiration in preterm infants. Acta Paediatr 2003;92:721-7.

6 deCarvalho M, Anderson DM, Giangreco A, et al. Frequency of milk expression and milk production by mothers of nonnursing premature neonates. Am J Dis Child 1985; $139: 483$

7 Hopkinson JM, Schanler RJ, Garza C. Milk production by mothers of premature infants. Pediatrics 1988;81:815-20.

8 Hill PD, Aldag JC, Chatterton RT. Initiation and frequency of pumping and milk production in mothers of non-nursing preterm infants. J Hum Lact 2001;17:9-13.

9 Hoban R, Bigger H, Schoeny M, et al. Milk Volume at 2 Weeks Predicts Mother's Own Milk Feeding at Neonatal Intensive Care Unit Discharge for Very Low Birthweight Infants. Breastfeed Med 2018;13:135-41.

10 Sisk P, Quandt S, Parson N, et al. Breast Milk Expression and Maintenance in Mothers of Very Low Birth Weight Infants: Supports and Barriers. Journal of Human Lactation 2010;26:368-75

11 Daly SE, Kent JC, Owens RA, et al. Frequency and degree of milk removal and the short-term control of human milk synthesis. Exp Physiol 1996;81:861-75.

12 Arthur PG, Hartmann PE, Smith M. Measurement of the milk intake of breast-fed infants. J Pediatr Gastroenterol Nutr 1987;6:758-63.

13 Moya J, Phillips L, Schuda L, et al. In exposure factors handbook. Washington, WA, USA: US Environmental Protection Agency, 2011.

14 R Core Team. R: A Language and Environment for Statistical Computing. [Internet]. Vienna, Australia. 2018 http://www.r-project.org/.

15 Daly SE, Owens RA, Hartmann PE. The short-term synthesis and infant-regulated removal of milk in lactating women. Exp Physiol 1993;78:209-20.

16 Knight CH, Peaker M, Wilde CJ. Local control of mammary development and function. Rev Reprod 1998;3:104-12.

17 Kent JC, Gardner H, Lai CT, et al. Hourly Breast Expression to Estimate the Rate of Synthesis of Milk and Fat. Nutrients 2018;10:1144.

18 Lai CT, Hale TW, Simmer K, et al. Measuring milk synthesis in breastfeeding mothers. Breastfeed Med 2010;5:103-7

19 Prime DK, Garbin CP, Hartmann PE, et al. Simultaneous breast expression in breastfeeding women is more efficacious than sequential breast expression. Breastfeed Med 2012;7:442-7

20 Hill PD, Aldag JC, Chatterton RT, et al. Comparison of milk output between mothers of preterm and term infants: the first 6 weeks after birth. J Hum Lact 2005;21:22-30. 